\title{
Prognostic factors, symptom evolution, and quality of life of posttraumatic trigeminal neuropathy
}

Fréderic Van der Cruyssen ${ }^{\mathrm{a}, \mathrm{b}, \star}$, Frederik Peeters ${ }^{\mathrm{a}}$, Antoon De Laat ${ }^{\mathrm{c}}$, Reinhilde Jacobs ${ }^{\mathrm{b}, \mathrm{d}}$, Constantinus Politis ${ }^{\mathrm{a}, \mathrm{b}}$, Tara Renton ${ }^{\mathrm{e}}$

\begin{abstract}
Neurosensory disturbances (NSDs) caused by injury to the trigeminal nerve can affect many aspects of daily life. However, factors affecting the persistence of NSDs in patients with posttraumatic trigeminal neuropathies (PTTNs) remain largely unknown. The identification of such risk factors will allow for the phenotyping of patients with PTTNs, which is crucial for improving treatment strategies. We therefore aimed to identify the prognostic factors of NSD persistence, pain intensity, and quality of life (QoL) in patients with PTTNs and to use these factors to create a prognostic prediction model. We first performed a bivariate analysis using retrospective longitudinal data from 384 patients with NSDs related to posttraumatic injury of the trigeminal nerve (mean follow-up time: $322 \pm 302$ weeks). Bivariate and multivariate analyses were performed. The multivariable prediction model to predict persistent NSDs was able to identify $76.9 \%$ of patients with persistent NSDs, with an excellent level of discrimination (area under the receiver operating characteristic curve: 0.84 ; sensitivity: $81.8 \%$; specificity: $70.0 \%$ ). Furthermore, neurosensory recovery was significantly associated with sex; injury caused by local anesthesia, extraction, third molar surgery, or endodontic treatment; and the presence of thermal hyperesthesia. Pain intensity and QoL analysis revealed several factors associated with higher pain levels and poorer QoL. Together, our findings may aid in predicting patient prognosis after dental, oral, and maxillofacial surgery and might lead to personalized treatment options and improved patient outcomes.
\end{abstract}

Keywords: Posttraumatic trigeminal nerve injury, Neuropathic pain, Prognosis, Predictive factors, Neurosensory profile

\section{Introduction}

The trigeminal nerve has the largest representation in the human sensory cortex, reflecting the disproportionate sensory input that comes from the orofacial region. The reception of sensory input from trigeminal dermatomes protects vital processes that underpin our survival. ${ }^{34}$ Pain in the trigeminal nerve area interferes with eating, speaking, sleeping, applying makeup, shaving, kissing, tooth brushing, and drinking-just about every daily

Sponsorships or competing interests that may be relevant to content are disclosed at the end of this article.

a Department of Oral and Maxillofacial Surgery, University Hospitals Leuven, Leuven, Belgium, ' ${ }^{b}$ OMFS-IMPATH Research Group, Department of Imaging and Pathology, Faculty of Medicine, University Leuven, Leuven, Belgium, ' Department of Oral Health Sciences, KU Leuven and Department of Dentistry, University Hospitals, Leuven, Belgium, ' Department of Dental Medicine, Karolinksa Institutet, Stockholm, Sweden, e Department of Oral Surgery, King's College London Dental Institute, London, United Kingdom

*Corresponding author. Address: Department of Oral and Maxillofacial Surgery University Hospitals Leuven, Kapucijnenvoer 33, 3000 Leuven, Belgium. Tel.: +32 163324 62. E-mail address: frederic.vandercruyssen@uzleuven.be (F. Van der Cruyssen).

Supplemental digital content is available for this article. Direct URL citations appear in the printed text and are provided in the HTML and PDF versions of this article on the journal's Web site (www. painjournalonline.com).

PAIN 00 (2021) 1-15

Copyright @ 2021 The Author(s). Published by Wolters Kluwer Health, Inc. on behalf of the International Association for the Study of Pain. This is an open access article distributed under the terms of the Creative Commons Attribution-Non CommercialNo Derivatives License 4.0 (CCBY-NC-ND), where it is permissible to download and share the work provided it is properly cited. The work cannot be changed in any way or used commercially without permission from the journal.

http://dx.doi.org/10.1097/j.pain.0000000000002408 routine that we take for granted. As a result, this has a significant negative effect on patients' self-image, QoL, and psychology. ${ }^{9}$ Renton et al. reported that $36 \%$ of patients with posttraumatic trigeminal neuropathic pain (PTNP) show signs of depression and a similar proportion of patients have a clinically significant anxiety level. ${ }^{26,41}$ Apart from patient morbidity, there is also a societal and economic burden caused by reduced labor force participation and absenteeism. ${ }^{23}$

Posttraumatic neuropathies can be painful or nonpainful and are an increasingly recognized postsurgical issue for patients. ${ }^{20}$ In the orofacial region, these conditions have been defined by the International Classification of Orofacial Pain (ICOP), which is endorsed by both the International Headache Society and the International Association for the Study of Pain. ${ }^{18}$ Posttraumatic trigeminal neuropathic pain may arise after injury to the sensory nerves. It can cause sensory abnormalities associated with hyposensitivity or hypersensitivity, with allodynia and hyperalgesia. When no neuropathic area is evident, patients may fit the criteria of chronic postsurgical pain (CPSP). This is a wellrecognized complication after routine surgery, with significant rates of pain affecting patients who have undergone limb amputation, breast surgery, thoracotomy, and cardiac surgery. ${ }^{20}$ However, questions remain as to whether CPSP and PTNP are different phenotypes of the same condition. ${ }^{15}$

Risk factors for CPSP are well-established and include both patient-related and surgery-related factors. ${ }^{19}$ To date, there is limited evidence regarding the presentation and outcome of patients with posttraumatic trigeminal neuropathies (PTTNs), and potential prognostic predictors have not been thoroughly investigated. ${ }^{3,4}$ Likely predictors for chronification can be identified 
in the preoperative, intraoperative, and postoperative periods and cover 6 broad domains: genetic, demographic, psychosocial, pain, clinical, and surgical factors. ${ }^{6,37}$ Most studies have focused on the preoperative risk factors of trigeminal neurosensory disturbances (NSDs). ${ }^{10,11,33,47}$ The identification of these risk factors is important because they may allow the phenotyping of patients in the future. This phenotyping is crucial if we wish to improve treatment outcomes. ${ }^{14}$ As yet, there have been no large longitudinal studies investigating the outcomes of posttraumatic trigeminal nerve injuries. Furthermore, prognostic prediction models are lacking.

The aim of this study was to identify prognostic factors in patients with PTTNs by running a multivariable analysis based on the retrospective longitudinal data of a large patient cohort from a tertiary referral center in Belgium (University Hospitals Leuven) and to build a prognostic prediction model using these data. We aimed to determine if and when NSDs persist and how symptoms evolve over time. In addition, we aimed to predict quality of life (QoL) and compare clinical features, pain quality, and characteristics between low and high pain intensity cohorts.

\section{Methods}

\subsection{Source of data}

The data used in this study originated from the TrigNerVeBeUK (TNVBUK) registry. The study protocol was approved by the institute's ethical committee (S62333, ClinicalTrials.gov identifier NCT04612855). The study was conducted according to the Transparent Reporting of a multivariable prediction model for Individual Prognosis Or Diagnosis (TRIPOD) statement. ${ }^{8}$ Data were retrieved from patient charts at the Department of Oral and Maxillofacial Surgery and the Orofacial Pain Clinic between October 2018 and January 2019.

\subsection{Patient selection}

The charts of patient visiting between January 2010 and October 2018 were screened for postraumatic (including iatrogenic) injury to branches of the trigeminal nerve. No age restrictions were made. Inclusion criteria were as follows: presentation with a posttraumatic injury of the trigeminal nerve or its branches and a clinical neurological diagnosis of a neurosensory deficit in the distribution of the trigeminal nerve according to previously described methods, ${ }^{34}$ which are summarized in section 2.3. Patients were excluded if the deficit presented in a region outside of the innervation zone of the trigeminal nerve or if the follow-up time was less than 3 months. Patients diagnosed with neurosensory disturbances (NSDs) after orthognathic surgery were excluded. Orthognathic surgery patients are tracked in a different care pathway at the authors' clinic. Including these patients would result in introducing selection bias.

\subsection{Clinical assessment method}

The neuro-assessment protocol was conducted according to previously reported algorithms ${ }^{28,34}$ and included qualitative sensory testing by mapping the neurosensory disturbance over the affected dermatome using blunt forceps (intraorally and/or extraorally, depending on the affected nerve). This was performed using a running needle technique from normal towards neuropathic area. The patient was asked to raise their hand as soon as the sensation was not perceived normal. The borders were marked with a pen to allow the next assessments to be conducted within the neuropathic area vs the contralateral side. In case of bilateral involvement, the adjacent dermatome served as control. Light touch assessment was performed using a cotton bud (to assess subjective function and the presence of mechanical allodynia) and sharp or blunt discrimination by using a dental probe (to assess mechanical hyperalgesia and hyperpathia). Each stimulus was presented 5 times and 2 scores of 5 were noted if the patient correctly identified the presence of light touch and discriminated correctly between sharp or blunt. It was noted whether mechanical allodynia or hyperalgesia was present. Two-point discrimination to assess mechanoperception was conducted using a staircase method of levels starting with closed calipers and stepwise increasing separation of $1 \mathrm{~mm}$ until a reliable level was reached. If a thermal component (hot or cold allodynia or hyperalgesia) was described, this was also recorded. In addition, hyperesthesia (allodynia, hyperalgesia, and hyperpathia) or hypoesthesia (reduced sensation or anesthesia) was recorded. An NSD was defined as abnormal according to the algorithm proposed by Miloro. ${ }^{28}$ This meant an abnormal or absent response to any of the conducted sensory tests compared with the contralateral side or the adjacent trigeminal dermatome in case of bilateral involvement. Two-point discrimination was considered abnormal if it exceeded $15 \mathrm{~mm}^{35}$ Neuropathic pain was diagnosed in accordance with a study by Finnerup et al. ${ }^{12}$

Patients were categorized into painful PTTN and nonpainful PTTN groups based on the recent ICOP criteria for PTNP. ${ }^{18}$ Patients with nonpainful PTTN fulfilled all ICOP criteria except criterion $\mathrm{A}$ : pain in a neuroanatomically plausible area within the trigeminal distribution.

Based on the symptoms reported during history taking and the clinical findings, including qualitative neurosensory testing, patients were further stratified into the following sensory profiles: sensory loss, thermal hyperalgesia or allodynia (hereafter referred to as "thermal hyperesthesia"), mechanical hyperalgesia or allodynia (hereafter referred to as "mechanical hyperesthesia"), and combinations (hereafter referred to as "mixed").

\subsection{Predictors}

Preoperative predictor variables included age, sex, and smoker status. The number of other pain diagnoses in a patient's history was considered a separate variable.

Perioperative variables included the different affected trigeminal nerve branches (the inferior alveolar nerve, the maxillary nerve or its infraorbital and superior alveolar terminal branches, or the lingual nerve) and the initiating event (local anesthesia, third molar surgery, tooth extraction, endodontic treatment, or dental implant placement).

Postoperative variables were the duration of symptoms (constant or intermittent), presence of pain (yes/no), pain visual analog scale (VAS) score (Likert scale ranging from 0 to 10, with 0 meaning no pain and 10 meaning the most severe pain imaginable), and sensory profile (sensory loss, thermal hyperesthesia, mechanical hyperesthesia, or mixed). Only treatments initiated for their condition were considered, and these were further categorized into any treatment (yes/no), systemic (yes/ no), topical (yes/no), and surgical (yes/no). Finally, QoL was assessed at the end of the follow-up period using the EQ-5D-5L questionnaire, which considers 5 domains (mobility, self-care, usual activities, pain/discomfort, and anxiety/depression) on a 
5-point ordinal scale (0: no problems; 1 : slight problems; 2 : moderate problems; 3: severe problems; and 4: extreme problems). These domains were dichotomized into no problems (score 0) and any problems (scores 1-4). Patients also indicated their self-rated health on a VAS, from 0 (worst) to 100 (the best health they could imagine).

\subsection{Prediction models of outcome variables}

Three regression models were constructed. First, time to complete symptom resolution was predicted. For this outcome, the duration of symptoms (in weeks) since the initiating event was calculated. Patients who continued to experience NSDs 3 months postsurgery were considered to have persistent NSDs; if not, they were considered to have temporary NSDs, as suggested by the International Association for the Study of Pain and International Headache Society criteria. ${ }^{17,38}$ Patients were seen on a regular basis until symptom resolution. If no symptom resolution occurred, most patients were followed up on a three-month basis until the end of data accrual. Improvements were recorded from the last follow-up visit on a categorical scale as worse, same, some improvement, improved a lot but still has symptoms, or improved a lot with no more symptoms. No differentiation was made between improvement in pain or in NSD. All clinical observations were made by the clinical staff, who were independent from the investigators.

In a second model, we predicted QoL using the EQ-5D-5L selfrated health VAS score at final follow-up. The third model aimed to predict pain intensity at the final follow-up moment.

\subsection{Comparison of low vs moderate to severe pain intensity cohorts}

Based on the pain VAS score (ranging from 0 to 10) assessed during the last follow-up moment, patients were categorized into low $(<5)$ or moderate to severe $(\geq 5)$ pain intensity cohorts. This allowed for a comparison of clinical features, pain quality, and pain characteristics between both cohorts.

\subsection{Sample size and missing data}

No similar studies have been conducted to be able to estimate the incidence and frequency of persistent NSDs in our study population. However, based on simulation studies, a minimum of 10 events per variable are required, rendering a sample size of 230 patients. ${ }^{31,46}$ Missing data were handled by listwise exclusion to build the logistic regression model after verifying the randomness and frequency of missing values.

\subsection{Statistical analysis}

All data were handled by a certified statistician using SPSS version 25.0 (IBM Corp, Armonk, NY).

The exploratory data analysis consisted of 5 steps. (1) Descriptive data analysis by calculating the means, SDs, counts, and frequencies. (2) Bivariate analysis, for which the Kendall tau-b correlation was used to determine the relationship between continuous variables and the outcome variables: persistence of NSD and pain intensity. A chi-squared test for association was conducted between binomial variables. If expected cell counts were less than 5 , a Fisher exact test was used. Strength of association was evaluated using the Cramér V test. (3) Multivariable modeling by performing binomial logistic regression to ascertain the effects of age, sex, initiating event, injured nerve branch, VAS pain score, and sensory profile on the likelihood that participants had a persistent trigeminal nerve injury. Similarly, the effects of age, sex, initiating event, injured nerve branch, sensory profile, and persistence of NSDs were assessed on the likelihood that participants reported moderate to severe pain intensities. Variables were selected based on the bivariate analysis $(P<0.05)$, strength of correlation, and after discussion by the investigators. Treatment effects were simulated in both bivariate and multivariable models. Linearity of the continuous variables with respect to the logit of the dependent variable was assessed through the Box-Tidwell procedure. ${ }^{5}$ A Bonferroni correction was applied using all terms in the model. ${ }^{43}$ Sensitivity, specificity, and positive predictive value (PPV) and negative predictive value (NPV) were determined, as well as the area under the receiver operating characteristic curve $(A \cup C) .{ }^{16}$ Based on this assessment, all continuous independent variables were linearly related to the logit of the dependent variables. (4) A point-biserial correlation analysis was used to determine the relationship between the dichotomous predictors and the self-perceived health-related QoL after evaluation of normality (visual inspection of Q-Q plots) and equality of variances using the Levene test. In case assumptions were not met, the Kendall tau-b correlation test was used. For continuous independent variables, a Spearman correlation test was performed. (5) Multiple regression analysis was performed to predict the QoL from the above-mentioned predictors. Linearity was assessed by inspection of partial regression plots and a plot of studentized residuals against predicted values. Independence of residuals was verified using a Durbin-Watson test. Multicollinearity was set at tolerance values greater than 0.2. The assumption of normality was assessed on a $Q-Q$ plot.

We used a bootstrap method for internal validation of the selected variables. A random selection with replacement of 1000 samples was derived. The $\beta$ coefficient and 95\% confidence intervals were then calculated for each variable.

Finally, Kaplan-Meier curves were constructed to assess the effects of risk factors on persistent NSDs over time. In consultation with the investigators, the following factors were withheld for the Kaplan-Meier analysis: age, sex, painful vs nonpainful PTTNs, initiating event, injured branch, and sensory profile. A correction for multiple comparisons was applied, and censoring percentages were analyzed. The pairwise log-rank test was used to detect any significant differences between the constructed curves. $P$ values smaller than 0.05 were considered statistically significant.

\section{Results}

\subsection{Population characteristics}

A total of 384 patients were included, with a mean follow-up time of $322 \pm 302$ weeks. Table 1 summarizes patient characteristics and the considered variables. Sixty percent of patients had a persistent trigeminal nerve injury. There were more females than males (66\% vs 34\%), and the mean age of patients was $50.1 \pm$ 16.6 years. The inferior alveolar nerve was most frequently damaged (45\%), followed by the maxillary nerve and its terminal branches (35\%). Third molar surgery was the causative procedure in $34 \%$ of all cases, followed by tooth extraction (29\%) and dental implant placement (19\%). Most patients had sensory loss (40\%) and pain (24\%), with a mean pain VAS score of 2.3 of 10. Treatments were variable and included over-the-counter 
analgesics in $65 \%$ of patients, followed by antidepressants (45\%). Opioids were used in $14 \%$ of patients. Eighteen percent of patients had some sort of topical treatment. In $8 \%$ of cases, a surgical intervention was performed. Improvement was seen in $42 \%$ of patients. In about half of the patients, symptoms remained the same or showed only some improvement. Half of the patients indicated some health-related problems on the EQ-5D-5L QoL questionnaire. The overall mean selfperceived health state was $70 \pm 20$.

\subsection{Bivariate analysis between temporary and persistent neurosensory disturbances}

Several patient-related and surgery-related predictors were significantly associated with persistent NSDs (Table 2). Bivariate analysis revealed that females had more persistent NSDs compared with males (odds ratio [OR] 2.23, 95\% confidence interval [Cl] 1.39-3.58, $P<0.0001$ ). Older age was associated with significantly higher rates of persistent NSDs (OR 1.03, 95\% $\mathrm{Cl} 1.02-1.05, P<0.0001)$. Lingual nerve injuries were associated with significant lower rates of persistent NSDs (OR 0.48, 95\% CI 0.27-0.85, $P<0.0001$ ). Maxillary nerve lesions were more associated with persistent NSDs (OR 3.05, 95\% Cl 1.80-5.18) than with temporary NSDs.

If the cause of NSD was the administration of local anesthesia, the OR for persistent NSDs was 0.08 (95\% Cl 0.02-0.36, $P<$ 0.0001 ), meaning that patients were less likely to sustain persistent NSDs. Likewise, third molar surgery had an unadjusted $\mathrm{OR}$ of 0.36 (95\% $\mathrm{Cl} 0.22-0.61, P<0.0001)$.

A persistent NSD was also associated with the presence of pain and higher pain VAS scores (OR 3.39, 95\% Cl 1.82-6.30, $P$ $<0.0005$ and OR 1.35, 95\% Cl 1.19-1.53, $P<0.0005$, respectively). In addition, the presence of thermal hyperesthesia was more frequent in the persistent NSD group (OR 5.10, 95\% Cl 1.97-13.25, $P<0.0005)$. Patients with mechanical hyperesthesia were twice as likely to have a persistent NSD (OR 2.10, 95\% Cl 1.24-3.54, $P<0.005)$

A higher number of pain diagnoses were also associated with the persistence of NSD (OR 26.20, 95\% Cl 1.58-434.99, $P<$ 0.0005). Moreover, lower QoL (a lower self-perceived health state, scored as a lower VAS score) was associated with persistent NSDs (OR 0.94, 95\% Cl 0.92-0.97, $P<0.0005$ ). Patients with persistent NSDs scored their current health state as $65 \pm 1.9$ of 100 , compared with $80 \pm 1.4$ in the cohort with temporary NSDs $(P<0.0005)$.

Presence of any treatment did not have a significant correlation with persistence. Yet, topical treatment did correlate (OR 7.73, 95\% Cl 3.01-19.85, $P<0.0005)$.

\subsection{Multivariable prediction model of persistent neurosensory deficits}

After the bivariate analysis of 23 variables (Table 2), 15 were entered into the logistic regression model. The logistic regression model was statistically significant $\left(\chi^{2}(15)=69.9, P<0.0005\right)$. The model explained $46 \%$ (Nagelkerke $R^{2}$ ) of the variance in persistent trigeminal nerve injuries and correctly classified $76.9 \%$ of cases. The sensitivity was $81.8 \%$, specificity was $70.0 \%$, PPV was $79.4 \%$, and NPV was $73.1 \%$.

Of the 15 predictor variables, 6 were statistically significant: sex; pain caused by local anesthesia, extraction, third molar surgery, or endodontic treatment; and the presence of thermal hyperesthesia (Table 3). The model showed an excellent level of
Table 1

Characteristics of $\mathbf{3 8 4}$ patients with posttraumatic trigeminal neuropathy.

\begin{tabular}{|c|c|c|c|}
\hline Characteristic (N) & $\mathbf{N}$ & Count (\%) & Mean (SD) \\
\hline $\begin{array}{l}\text { Gender } \\
\text { Male } \\
\text { Female }\end{array}$ & 373 & $\begin{array}{l}126(33.8) \\
247(66.2)\end{array}$ & \\
\hline Age & 373 & & $50.1(16.6)$ \\
\hline $\begin{array}{l}\text { Injured nerve } \\
\text { Inferior alveolar nerve } \\
\text { Lingual nerve } \\
\text { Maxillary nerve } \\
\text { Mandibular nerve } \\
\text { Inferior alveolar and maxillary nerve }\end{array}$ & $\begin{array}{l}367 \\
367 \\
367 \\
367 \\
367 \\
\end{array}$ & $\begin{array}{l}166(45.2) \\
53(14.4) \\
127(34.6) \\
10(2.7) \\
11(3.0) \\
\end{array}$ & \\
\hline $\begin{array}{l}\text { Initiating event } \\
\text { Local anesthesia } \\
\text { Third molar surgery } \\
\text { Tooth extraction } \\
\text { Endodontic treatment } \\
\text { Dental implant placement }\end{array}$ & $\begin{array}{l}252 \\
252 \\
252 \\
252 \\
252\end{array}$ & $\begin{array}{l}15(6.0) \\
86(34.1) \\
74(29.4) \\
30(11.9) \\
47(18.7) \\
\end{array}$ & \\
\hline $\begin{array}{l}\text { Clinical findings } \\
\text { Pain VAS score } \\
\text { Sensory profile } \\
\text { Pain } \\
\text { Sensory loss } \\
\text { Thermal hyperesthesia } \\
\text { Mechanical hyperesthesia } \\
\text { Mixed }\end{array}$ & $\begin{array}{l}185 \\
367\end{array}$ & $\begin{array}{l}87(23.7) \\
145(39.5) \\
14(3.8) \\
55(15.0) \\
66(18.0)\end{array}$ & $2.3(3.4)$ \\
\hline
\end{tabular}

\begin{tabular}{|c|c|c|c|}
\hline \multicolumn{4}{|l|}{ Treatment } \\
\hline Any treatment & 384 & & \\
\hline Yes & & 339 (88.3) & \\
\hline No & & $45(11.7)$ & \\
\hline Systemic treatment & 384 & & \\
\hline Over the counter analgetics & & $252(65.6)$ & \\
\hline Antiepileptics & & $104(27.1)$ & \\
\hline Antidepressants & & $174(45.3)$ & \\
\hline Benzodiazepines & & $66(17.2)$ & \\
\hline Opioids & & $54(14.1)$ & \\
\hline Topical treatment & 384 & $68(17.7)$ & \\
\hline Surgical treatment & 384 & $30(7.8)$ & \\
\hline \multicolumn{4}{|l|}{ Prognosis } \\
\hline Duration & 343 & & \\
\hline Temporary injury & & $111(28.9)$ & \\
\hline Persistent injury & & $232(60.4)$ & \\
\hline Improvement & 287 & & \\
\hline Worse & & $4(1.4)$ & \\
\hline Same & & $69(24.0)$ & \\
\hline Some improvement & & $92(32.1)$ & \\
\hline A lot of improvement, still symptoms & & $77(26.8)$ & \\
\hline A lot of improvement, no more symptoms & & $45(15.7)$ & \\
\hline Follow-up time in weeks & 322 & & $302(358)$ \\
\hline \multicolumn{4}{|l|}{ Quality of life (EQ-5D-5L) } \\
\hline \multicolumn{4}{|l|}{ Dimensions } \\
\hline No problems & 384 & $190(49.5)$ & \\
\hline Any problem & 384 & $194(50.5)$ & \\
\hline Health state & 190 & & 70.4 (19.8) \\
\hline
\end{tabular}

SD, standard deviation; VAS, visual analog scale.

discrimination (according to Hosmer et al. ) ${ }^{16}$ with an overall AUC of 0.84 (95\% Cl 0.79-0.90).

An individual risk of persistent NSDs may be calculated using the supplemental calculator (Supplemental Table 1, available at http://links.lww.com/PAIN/B435). The risk is calculated by the following formula: 


\section{Table 2}

Comparison of variables between patients with temporary and persistent neurosensory disturbances and the results of bivariate analyses assessing the relationship between patient-related and surgery-related factors and NSD cohorts.

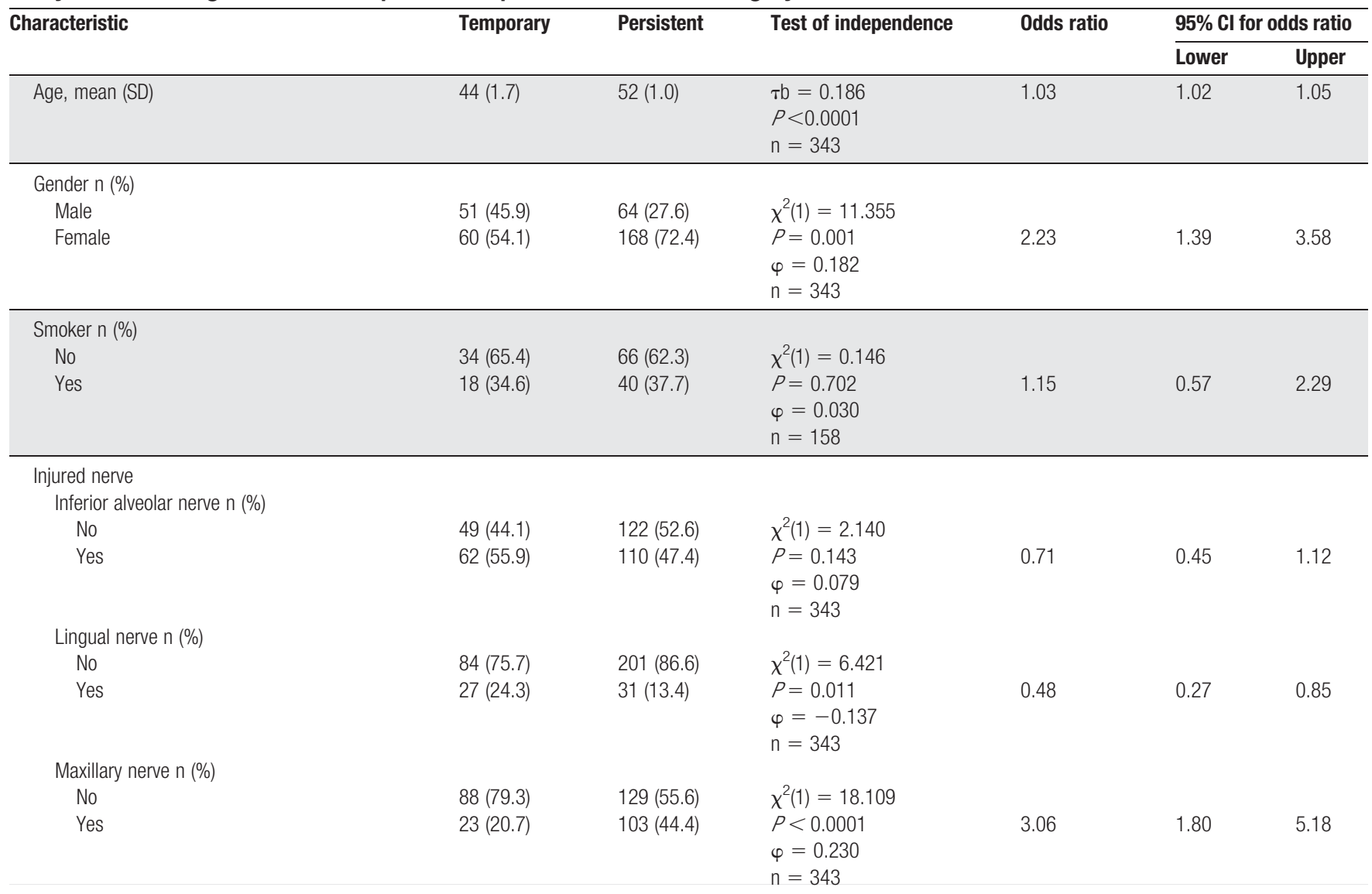

\begin{tabular}{|c|c|c|c|c|c|c|}
\hline \multicolumn{7}{|l|}{ Initiating event } \\
\hline \multicolumn{7}{|c|}{ Local anesthesia n (\%) } \\
\hline No & $100(90.1)$ & $230(99.1)$ & $\mathrm{FET}(1)$ & & & \\
\hline \multirow[t]{2}{*}{ Yes } & $11(9.9)$ & $2(0.9)$ & $P<0.0001$ & 0.08 & 0.02 & 0.36 \\
\hline & & & $\begin{array}{l}\varphi=-0.222 \\
\mathrm{n}=343\end{array}$ & & & \\
\hline \multicolumn{7}{|c|}{ Third molar surgery $n(\%)$} \\
\hline No & $72(64.9)$ & $194(83.6)$ & $\chi^{2}(1)=15.171$ & & & \\
\hline \multirow[t]{3}{*}{ Yes } & $39(35.1)$ & $38(16.4)$ & $P<0.0001$ & 0.36 & 0.22 & 0.61 \\
\hline & & & $\varphi=-0.210$ & & & \\
\hline & & & $n=343$ & & & \\
\hline \multicolumn{7}{|c|}{ Tooth extraction n (\%) } \\
\hline No & $90(81.1)$ & $189(81.5)$ & $\chi^{2}(1)=0.007$ & & & \\
\hline \multirow[t]{3}{*}{ Yes } & $21(18.9)$ & $43(18.5)$ & $P=0.932$ & 0.98 & 0.55 & 1.74 \\
\hline & & & $\varphi=-0.005$ & & & \\
\hline & & & $n=343$ & & & \\
\hline \multicolumn{7}{|c|}{ Endodontic treatment n (\%) } \\
\hline No & $102(91.9)$ & $212(91.4)$ & $\chi^{2(1)}=0.025$ & & & \\
\hline \multirow[t]{3}{*}{ Yes } & $9(8.1)$ & $20(8.6)$ & $P=0.873$ & 1.07 & 0.47 & 2.43 \\
\hline & & & $\varphi=0.009$ & & & \\
\hline & & & $n=343$ & & & \\
\hline \multicolumn{7}{|c|}{ Dental implant placement n (\%) } \\
\hline No & $101(91.0)$ & $196(84.5)$ & $\chi^{2(1)}=2.739$ & & & \\
\hline \multirow[t]{3}{*}{ Yes } & $10(9.0)$ & $36(15.5)$ & $P=0.098$ & 1.86 & 0.89 & 3.89 \\
\hline & & & $\varphi=0.089$ & & & \\
\hline & & & $n=343$ & & & \\
\hline \multicolumn{7}{|l|}{ Clinical findings } \\
\hline \multicolumn{3}{|l|}{ Duration n (\%) } & $\chi^{2}(1)=0.510$ & & & \\
\hline Constant & $73(90.1)$ & $161(87.0)$ & $P=0.475$ & & & \\
\hline Intermittent & $8(9.9)$ & $24(13.0)$ & $\varphi=0.044$ & 1.36 & 0.58 & 3.17 \\
\hline & & & $n=266$ & & & \\
\hline
\end{tabular}


Table 2 (continued)

\begin{tabular}{|c|c|c|c|c|c|c|}
\hline \multirow[t]{2}{*}{ Characteristic } & \multirow[t]{2}{*}{ Temporary } & \multirow[t]{2}{*}{ Persistent } & \multirow[t]{2}{*}{ Test of independence } & \multirow[t]{2}{*}{ Odds ratio } & \multicolumn{2}{|c|}{ 95\% Cl for odds ratio } \\
\hline & & & & & Lower & Upper \\
\hline Pain VAS score, mean (SD) & $0.8(0.3)$ & $3.6(0.4)$ & $\begin{array}{l}\tau b=0.367 \\
P<0.0005 \\
n=169\end{array}$ & 1.35 & 1.19 & 1.53 \\
\hline \multicolumn{7}{|l|}{ Pain n (\%) } \\
\hline No & $28(25.2)$ & $21(9.1)$ & $\chi^{2}(1)=16.039$ & & & \\
\hline Yes & $83(74.8)$ & $211(90.9)$ & $\begin{array}{l}p<0.0005 \\
\varphi=0.216 \\
n=343\end{array}$ & 3.39 & 1.82 & 6.30 \\
\hline \multicolumn{7}{|l|}{ Sensory loss n (\%) } \\
\hline No & $32(28.8)$ & $134(57.8)$ & $\chi^{2}(1)=25.160$ & & & \\
\hline Yes & $79(71.2)$ & $98(42.2)$ & $\begin{array}{l}P<0.0005 \\
\varphi=-2.71 \\
n=343\end{array}$ & 0.30 & 0.18 & 0.48 \\
\hline \multicolumn{7}{|l|}{ Thermal hyperesthesia n (\%) } \\
\hline No & 106 (95.5) & $187(80.6)$ & $\chi^{2}(1)=13.371$ & & & \\
\hline Yes & $5(4.5)$ & $45(19.4)$ & $\begin{array}{l}P<0.0005 \\
\varphi=0.197 \\
n=343\end{array}$ & 5.10 & 1.97 & 13.25 \\
\hline \multicolumn{7}{|l|}{ Mechanical hyperesthesia n (\%) } \\
\hline No & $87(78.4)$ & $147(63.4)$ & $\chi^{2}(1)=7.809$ & & & \\
\hline Yes & $24(21.6)$ & $85(36.6)$ & $\begin{array}{l}P=0.005 \\
\varphi=0.151 \\
n=343\end{array}$ & 2.10 & 1.24 & 3.54 \\
\hline Number of other pain diagnoses, mean (SD) & $0(0.0)$ & $0.2(0.04)$ & $\begin{array}{l}\tau b=0.188 \\
P<0.0005 \\
\mathrm{n}=343\end{array}$ & 26.20 & 1.58 & 434.99 \\
\hline \multicolumn{7}{|l|}{ Treatment } \\
\hline \multicolumn{7}{|l|}{ Any treatment $\mathrm{n}(\%)$} \\
\hline No & $13(11.7)$ & $19(8.2)$ & $\chi^{2}(1)=1.101$ & & & \\
\hline Yes & $98(88.3)$ & $213(91.8)$ & $\begin{array}{l}P=0.294 \\
\varphi=0.057 \\
\mathrm{n}=343\end{array}$ & 1.50 & 0.71 & 3.13 \\
\hline \multicolumn{7}{|l|}{ Systemic treatment $\mathrm{n}(\%)$} \\
\hline No & $16(14.4)$ & $25(10.8)$ & $\chi^{2}(1)=0.944$ & & & \\
\hline Yes & $95(85.6)$ & $207(89.2)$ & $\begin{array}{l}P=0.331 \\
\varphi=0.052 \\
n=343\end{array}$ & 1.40 & 0.71 & 2.73 \\
\hline \multicolumn{7}{|l|}{ Topical treatment n (\%) } \\
\hline No & $106(95.5)$ & $170(73.3)$ & $\chi^{2}(1)=23.583$ & & & \\
\hline Yes & $5(4.5)$ & $62(26.7)$ & $\begin{array}{l}P<0.0005 \\
\varphi=0.262 \\
n=343\end{array}$ & 7.73 & 3.01 & 19.85 \\
\hline \multicolumn{7}{|l|}{ Surgical treatment $\mathrm{n}(\%)$} \\
\hline No & $107(96.4)$ & $209(90.1)$ & $\chi^{2}(1)=4.122$ & & & \\
\hline Yes & $4(3.6)$ & $23(9.9)$ & $\begin{array}{l}\hat{P}=0.042 \\
\varphi=0.110 \\
n=343\end{array}$ & 2.94 & 0.99 & 8.73 \\
\hline \multicolumn{7}{|l|}{ Quality of life (EQ-5D-5L) } \\
\hline No problems & $52(46.8)$ & $101(43.5)$ & $\chi^{2}(1)=0.333$ & & & \\
\hline Any problem & 59 (53.2) & $131(56.5)$ & $\begin{array}{l}P=0.564 \\
\varphi=0.031 \\
n=343\end{array}$ & 1.41 & 0.73 & 1.80 \\
\hline Health state, mean (SD) & $80(1.4)$ & $65(1.9)$ & $\begin{array}{l}\tau b=-0.306 \\
P<0.0005 \\
\mathrm{n}=343\end{array}$ & 0.94 & 0.92 & 0.97 \\
\hline
\end{tabular}

Persistent means present for more than 3 months after the injury was inflicted.

$\varphi$, phi coefficient or Cramer V; $\tau$ b, Kendall tau-b correlation coefficient; Cl, confidence interval; FET, Fisher exact test.; NSD, neurosensory disturbance

$$
\text { risk of persistent } \mathrm{NSD}=\frac{e^{\text {risk score }}}{1+e^{\text {risk score }}}
$$

Where risk score is calculated as the sum of the intercept and the sum of the multiplication of the regression coefficients and their respective values.

\subsection{Bivariate and multivariable analyses of pain intensity}

After dichotomizing pain intensity into low and moderate to high pain levels, we found a significant correlation with age, sex, injured nerve (lingual and maxillary nerve), and initiating event (third molar surgery) (Table 4). The presence of NSDs, thermal or 


\begin{tabular}{|c|c|c|c|c|c|c|c|c|c|c|}
\hline \multicolumn{11}{|l|}{ Multivariable binomia } \\
\hline \multirow[t]{2}{*}{ Characteristic } & \multirow[t]{2}{*}{ B } & \multirow[t]{2}{*}{ SE } & \multirow[t]{2}{*}{ Wald } & \multirow[t]{2}{*}{$d f$} & \multirow[t]{2}{*}{$P$} & \multirow[t]{2}{*}{ Odds ratio } & \multicolumn{2}{|c|}{$\begin{array}{l}95 \% \text { Cl for odds } \\
\text { ratio }\end{array}$} & \multicolumn{2}{|c|}{$\begin{array}{l}95 \% \mathrm{CI} \text { after } \\
\text { bootstrap } \\
\text { resampling }\end{array}$} \\
\hline & & & & & & & Lower & Upper & Lower & Upper \\
\hline Gender & 1.02 & 0.41 & 6.28 & 1 & 0.012 & 2.78 & 1.25 & 6.20 & 0.85 & 1.22 \\
\hline Age & 0.01 & 0.01 & 0.40 & 1 & 0.530 & 1.01 & 0.98 & 1.04 & 0.01 & 0.01 \\
\hline \multicolumn{11}{|l|}{ Injured nerve } \\
\hline Inferior alveolar nerve & 1.09 & 0.96 & 1.29 & 1 & 0.255 & 2.99 & 0.45 & 19.67 & 1.03 & 1.17 \\
\hline Lingual nerve & 1.69 & 1.03 & 2.70 & 1 & 0.100 & 5.41 & 0.72 & 40.47 & 1.48 & 2.00 \\
\hline Maxillary nerve & 1.21 & 1.08 & 1.24 & 1 & 0.266 & 3.34 & 0.40 & 27.99 & 1.14 & 1.28 \\
\hline \multicolumn{11}{|l|}{ Initiating event } \\
\hline Local anesthesia & -3.21 & 1.27 & 6.33 & 1 & 0.012 & 0.04 & 0.00 & 0.49 & -3.36 & -3.10 \\
\hline Third molar surgery & -1.25 & 0.55 & 5.09 & 1 & 0.024 & 0.29 & 0.10 & 0.85 & -1.38 & -1.11 \\
\hline Extraction & -2.00 & 0.68 & 8.53 & 1 & 0.003 & 0.14 & 0.04 & 0.52 & -2.03 & -1.98 \\
\hline Endodontic treatment & -2.84 & 1.24 & 5.24 & 1 & 0.022 & 0.06 & 0.01 & 0.67 & -2.90 & -2.79 \\
\hline Implant placement & -1.06 & 0.82 & 1.66 & 1 & 0.197 & 0.35 & 0.07 & 1.73 & -1.13 & -0.99 \\
\hline \multicolumn{11}{|l|}{ Clinical findings } \\
\hline Pain VAS score & 0.11 & 0.14 & 0.62 & 1 & 0.430 & 1.11 & 0.85 & 1.45 & 0.10 & 0.12 \\
\hline Pain & -0.14 & 0.46 & 0.09 & 1 & 0.767 & 0.87 & 0.35 & 2.16 & 0.37 & 0.15 \\
\hline Sensory loss & -1.23 & 1.01 & 1.50 & 1 & 0.221 & 0.29 & 0.04 & 2.10 & -1.41 & -1.10 \\
\hline Thermal hyperesthesia & 2.75 & 1.35 & 4.15 & 1 & 0.042 & 15.66 & 1.11 & 220.69 & 2.62 & 2.88 \\
\hline Mechanical hyperesthesia & 0.43 & 0.63 & 0.46 & 1 & 0.498 & 1.54 & 0.44 & 5.31 & 0.34 & 0.51 \\
\hline Constant & -0.18 & 1.51 & 0.01 & 1 & 0.905 & 0.83 & & & & \\
\hline
\end{tabular}

Gender is for females compared with males. AUC $=0.84, \chi^{2}(15)=69.9, P<0.0001$. A total of 1000 bootstrap subsamples were run.

$\mathrm{Cl}$, confidence interval; VAS: visual analog scale (0-10).

mechanical hyperesthesia, increased the odds of having a moderate to severe pain intensity. Logically, patients who received some treatment were more likely to experience moderate to severe pain (OR 4.69, 95\% Cl 1.06-20.76, $P=$ 0.026). On the other hand, third molar surgery was less likely to be associated with moderate to severe pain (OR 0.23, 95\% Cl 0.10$0.52, P<0.0005)$. A lower HrQoL was associated with moderate to severe pain intensity.

A logistic regression model was significant $(P<0.0001)$ with an AUC of 0.987 and Nagelkerke $R^{2}=87.3 \%$ (Table 5). The sensitivity and specificity were $96.2 \%$ and $98.3 \%$, respectively. Positive predictive value and NPV were 96.2\% and $98.4 \%$, respectively. We used the same input variables as in the previous regression model (replacing the pain variables by persistent NSDs). None of the individual features showed a significant contribution to the model except sensory loss $(P=0.002)$. In addition, we noted bootstrap confidence intervals that were largely different from the sample distribution. A risk score can be calculated using our tool given in Supplemental Table 1 (available at http://links.Iww.com/PAIN/B435).

\subsection{Bivariate and multivariable analyses of QoL}

Bivariate analysis revealed that the following variables were significantly associated with the QoL health state: age, sex, injured nerve (lingual and maxillary nerve), initiated by third molar surgery, persistence of NSD, sensory loss phenotype, and number of other pain diagnoses (Table 6). Quality of life was adversely affected when maxillary nerve lesions were present, when an NSD was persistent, or when multiple pain diagnoses were present.

The multiple regression model to predict QoL was statistically significant $F(15,77)=4.47, P<0.0005$. The adjusted $R^{2}$ was
0.361. Following variables were significant to the prediction: initiating event (third molar surgery and implant-related injury), VAS pain score, and presence of any treatment, $P<0.05$. Multicollinearity was present between any treatment and systematic treatment. After backwards regression analysis, only any treatment and the previously mentioned predictors (age, sex, injured nerve, initiating events, sensory profiles, and pain VAS score) were taken forward into the regression model. The results are summarized in Table 7. An individual QoL health state prediction may be calculated using the supplemental calculator (Supplemental Table 1, available at http://links.Iww.com/PAIN/ B435).

\subsection{Kaplan-Meier distributions}

Pairwise comparisons of Kaplan-Meier distributions revealed a statistically significant difference in NSD frequency over time between sex, age, painful and nonpainful PTTNs, initiating event, injured nerve, and sensory profile (Fig. 1). All survival distributions were significantly different (log-rank test $P<$ 0.0005). Older age, female gender, and a diagnosis of painful PTTNs all negatively affected the time to symptom resolution. Most improvement was observed during the first 20 weeks after injury. Little improvement was seen after 60 weeks. Painful PTTNs showed less tendency for recovery of NSDs, with $86.2 \%$ of patients still complaining of NSDs after 2 years. However, improvement continued to be observed even when symptoms were long-standing.

Patients with lingual nerve injuries had the best long-term outcomes, with only 44\% still experiencing NSDs after 2 years; again, most improvement was seen in the first 20 weeks. By contrast, patients with a maxillary nerve lesion reported almost no improvement of NSDs over time (92\% still experienced NSDs 


\section{Table 4}

Bivariate correlation analysis between cohorts with low pain intensity and moderate to severe pain intensity.

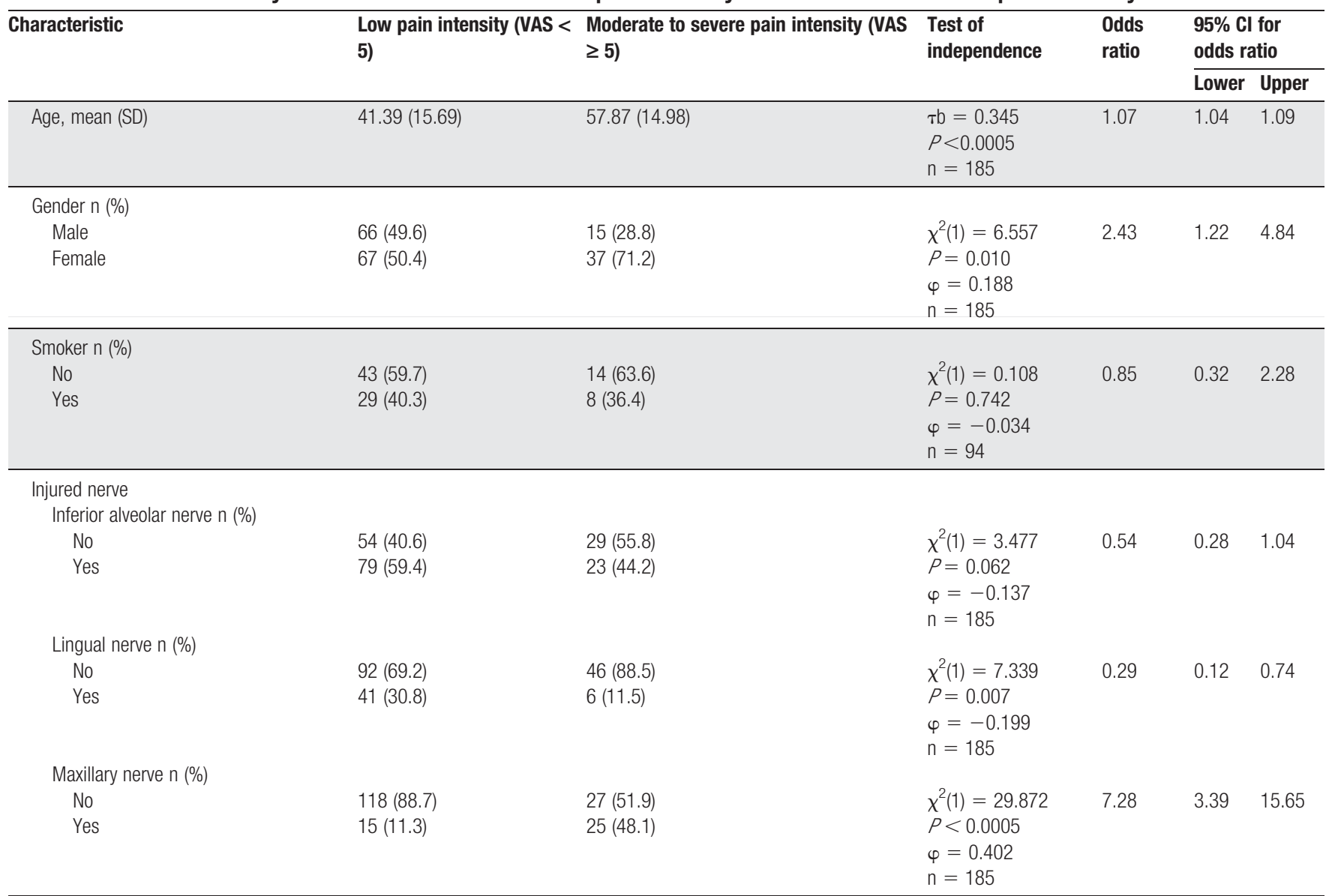

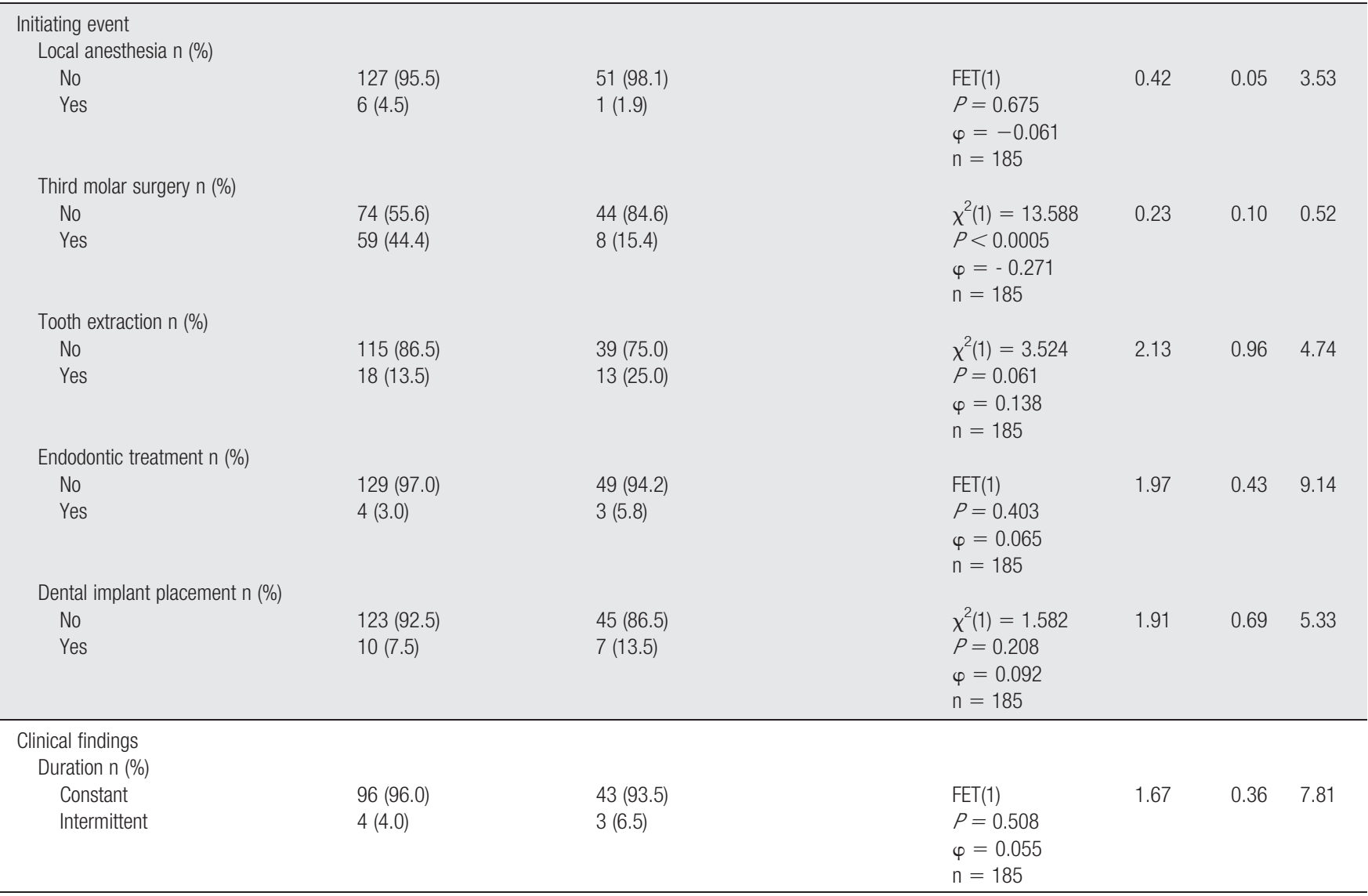


Table 4 (continued)

\begin{tabular}{|c|c|c|c|c|c|c|}
\hline \multirow[t]{2}{*}{ Characteristic } & \multirow[t]{2}{*}{$\begin{array}{l}\text { Low pain intensity (VAS < } \\
\text { 5) }\end{array}$} & \multirow[t]{2}{*}{$\begin{array}{l}\text { Moderate to severe pain intensity (VAS } \\
\geq 5 \text { ) }\end{array}$} & \multirow[t]{2}{*}{$\begin{array}{l}\text { Test of } \\
\text { independence }\end{array}$} & \multirow[t]{2}{*}{$\begin{array}{l}\text { Odds } \\
\text { ratio }\end{array}$} & \multicolumn{2}{|c|}{$\begin{array}{l}95 \% \mathrm{Cl} \text { for } \\
\text { odds ratio }\end{array}$} \\
\hline & & & & & Lower & Upper \\
\hline \multicolumn{7}{|l|}{ Persistency n (\%) } \\
\hline Temporary & $64(53.8)$ & $6(12.0)$ & $\chi^{2}(1)=25.330$ & \multirow[t]{2}{*}{8.53} & \multirow[t]{2}{*}{3.38} & \multirow[t]{2}{*}{21.54} \\
\hline Persistent & $55(46.2)$ & $44(88.0)$ & $\begin{array}{l}P<0.0005 \\
\varphi=0.387 \\
n=169\end{array}$ & & & \\
\hline \multicolumn{7}{|l|}{ Sensory loss n (\%) } \\
\hline No & $12(9.0)$ & $41(78.8)$ & $\chi^{2}(1)=89.162$ & \multirow[t]{4}{*}{0.03} & \multirow[t]{4}{*}{0.01} & \multirow[t]{4}{*}{0.07} \\
\hline Yes & $121(91.0)$ & $11(21.2)$ & $P<0.0005$ & & & \\
\hline & & & $\varphi=-0.694$ & & & \\
\hline & & & $\mathrm{n}=185$ & & & \\
\hline \multicolumn{7}{|l|}{ Thermal hyperesthesia n (\%) } \\
\hline No & $126(94.7)$ & $39(75.0)$ & $\chi^{2}(1)=15.103$ & \multirow[t]{4}{*}{6.00} & \multirow[t]{4}{*}{2.24} & \multirow[t]{4}{*}{16.09} \\
\hline Yes & $7(5.3)$ & $13(25.0)$ & $P<0.0005$ & & & \\
\hline & & & $\varphi=0.286$ & & & \\
\hline & & & $\mathrm{n}=185$ & & & \\
\hline \multicolumn{7}{|l|}{ Mechanical hyperesthesia $\mathrm{n}(\%)$} \\
\hline No & $120(90.2)$ & $24(46.2)$ & $\chi^{2}(1)=42.092$ & 10.77 & 4.89 & 23.74 \\
\hline Yes & $13(9.8)$ & $28(53.8)$ & $P=0.005$ & & & \\
\hline & & & $\varphi=0.477$ & & & \\
\hline & & & $\mathrm{n}=185$ & & & \\
\hline Number of other pain diagnoses, mean & $0.09(0.42)$ & $0.15(0.61)$ & $\tau b=0.047$ & 1.29 & 0.69 & 2.40 \\
\hline (SD) & & & $P=0.522$ & & & \\
\hline & & & $\mathrm{n}=185$ & & & \\
\hline Treatment & & & & & & \\
\hline Any treatment $\mathrm{n}(\%)$ & & & & & & \\
\hline No & $21(15.8)$ & $2(3.8)$ & $\mathrm{FET}(1)$ & 4.69 & 1.06 & 20.76 \\
\hline Yes & $112(84.2)$ & $50(96.2)$ & $P=0.026$ & & & \\
\hline & & & $\varphi=0.163$ & & & \\
\hline & & & $\mathrm{n}=185$ & & & \\
\hline Systemic treatment $\mathrm{n}(\%)$ & & & & & & \\
\hline No & $25(18.8)$ & $3(5.8)$ & $\mathrm{FET}(1)$ & 3.78 & 1.09 & 13.12 \\
\hline Yes & $108(81.2)$ & 49 (94.2) & $P=0.038$ & & & \\
\hline & & & $\varphi=0.163$ & & & \\
\hline & & & $n=185$ & & & \\
\hline Topical treatment n (\%) & & & & & & \\
\hline No & $125(94.0)$ & $35(67.3)$ & $\chi^{2}(1)=22.764$ & 7.59 & 3.02 & 19.05 \\
\hline Yes & $8(6.0)$ & $17(32.7)$ & $P<0.0005$ & & & \\
\hline & & & $\varphi=0.351$ & & & \\
\hline & & & $\mathrm{n}=185$ & & & \\
\hline Surgical treatment $\mathrm{n}(\%)$ & & & & & & \\
\hline No & $125(94.0)$ & 50 (96.2) & $\mathrm{FET}(1)$ & 0.63 & 0.13 & 3.05 \\
\hline Yes & $8(6.0)$ & $2(3.8)$ & $P=0.728$ & & & \\
\hline & & & $\varphi=-0.043$ & & & \\
\hline & & & $n=185$ & & & \\
\hline Quality of life (EQ-5D-5L) & & & & & & \\
\hline Dimensions n (\%) & & & & & & \\
\hline No problems & $65(48.9)$ & $25(48.1)$ & $\chi^{2}(1)=0.009$ & 1.03 & 0.54 & 1.96 \\
\hline Any problem & $68(51.1)$ & $27(51.9)$ & $P=0.923$ & & & \\
\hline & & & $\varphi=0.007$ & & & \\
\hline & & & $\mathrm{n}=185$ & & & \\
\hline Health state, mean (SD) & 79.31 (12.66) & 59.77 (24.88) & $\tau b=-0.339$ & 0.94 & 0.91 & 0.97 \\
\hline & & & $P<0.0005$ & & & \\
\hline & & & $n=185$ & & & \\
\hline
\end{tabular}

$\varphi$, phi coefficient or Cramer V; $\tau b$, Kendall tau-b correlation coefficient; Cl, confidence interval; FET, Fisher exact test; VAS, visual analogue scale.

after 2 years). For inferior alveolar nerve lesions, a persistent NSD was reported in $64 \%$ of cases after 2 years.

When comparing the most frequent initiating injury events, most NSDs after local anesthesia administration injury resolved within 40 weeks, although $25 \%$ of patients still experienced NSDs after 2 years. For injuries after third molar surgery, $47 \%$ of patients still reported NSDs after 2 years. Endodontic-related, implantrelated, or extraction-related injuries had a worse course of symptoms, with around $80 \%$ of patients still experiencing NSDs after 2 years. Implant-related injuries were considered the worst 
Table 5

Multivariable binomial regression model predicting moderate to severe pain intensity based on predetermined patient-related and surgery-related factors.

\begin{tabular}{|c|c|c|c|c|c|c|c|c|c|c|}
\hline \multirow[t]{2}{*}{ Characteristic } & \multirow[t]{2}{*}{ B } & \multirow[t]{2}{*}{ SE } & \multirow[t]{2}{*}{ Wald } & \multirow[t]{2}{*}{$d f$} & \multirow[t]{2}{*}{$P$} & \multirow[t]{2}{*}{ Odds ratio } & \multicolumn{2}{|c|}{$95 \% \mathrm{Cl}$ for odds ratio } & \multicolumn{2}{|c|}{$\begin{array}{l}95 \% \mathrm{Cl} \text { after } \\
\text { bootstrap } \\
\text { resampling }\end{array}$} \\
\hline & & & & & & & Lower & Upper & Lower & Upper \\
\hline Gender & 1.66 & 1.49 & 1.24 & 1 & 0.266 & 5.27 & 0.28 & 98.50 & -96.64 & 155.48 \\
\hline Age & -0.02 & 0.05 & 0.17 & 1 & 0.684 & 0.98 & 0.90 & 1.08 & -2.65 & 3.58 \\
\hline \multicolumn{11}{|l|}{ Injured nerve } \\
\hline Inferior alveolar nerve & 3.67 & 2.51 & 2.15 & 1 & 0.143 & 39.33 & 0.29 & 5356.36 & -116.35 & 268.61 \\
\hline Lingual nerve & 0.19 & 3.10 & 0.00 & 1 & 0.951 & 1.21 & 0.00 & 521.74 & -172.87 & 205.49 \\
\hline Maxillary nerve & 4.23 & 2.91 & 2.11 & 1 & 0.146 & 68.64 & 0.23 & $20,561.07$ & -121.30 & 391.54 \\
\hline \multicolumn{11}{|l|}{ Initiating event } \\
\hline Local anesthesia & -23.12 & $17,828.28$ & 0.00 & 1 & 0.999 & 0.00 & 0.00 & 0.00 & -315.92 & 261.90 \\
\hline Third molar surgery & 1.87 & 2.49 & 0.56 & 1 & 0.453 & 6.47 & 0.05 & 842.36 & -42.09 & 277.56 \\
\hline Extraction & 2.39 & 2.48 & 0.93 & 1 & 0.335 & 10.94 & 0.09 & 1413.70 & -95.41 & 163.33 \\
\hline Endodontic treatment & -0.34 & 2.54 & 0.02 & 1 & 0.893 & 0.71 & 0.01 & 102.56 & -129.69 & 324.02 \\
\hline Implant placement & 1.20 & 2.10 & 0.33 & 1 & 0.569 & 3.31 & 0.05 & 203.96 & -92.38 & 223.41 \\
\hline \multicolumn{11}{|l|}{ Clinical findings } \\
\hline Persistent NSD & 1.04 & 2.87 & 0.13 & 1 & 0.717 & 2.83 & 0.00 & 780.63 & -105.61 & 128.41 \\
\hline Sensory loss & -6.36 & 2.07 & 9.45 & 1 & 0.002 & 0.00 & 0.33 & 0.10 & -422.31 & -4.01 \\
\hline Thermal hyperesthesia & 2.01 & 1.58 & 1.61 & 1 & 0.205 & 7.42 & 0.03 & 164.90 & -84.15 & 117.93 \\
\hline Mechanical hyperesthesia & 2.05 & 2.78 & 0.54 & 1 & 0.462 & 7.74 & 0.03 & 1797.92 & -92.20 & 165.55 \\
\hline Any treatment & 8.79 & 6.27 & 1.96 & 1 & 0.161 & 6553.60 & 0.03 & $1,43 \mathrm{E}+12$ & -40.56 & 550.21 \\
\hline EQ-5D Health state & -0.13 & 0.09 & 2.33 & 1 & 0.127 & 0.88 & 0.74 & 1.04 & -16.71 & 0.25 \\
\hline Constant & -2.58 & 7.52 & 0.12 & 1 & 0.732 & 0.08 & & & & \\
\hline
\end{tabular}

Gender is for females compared with males. AUC $=0.987, \chi^{2}(16)=83.221, P<0.0001$. A total of 1000 bootstrap subsamples were run.

$\mathrm{Cl}$, confidence interval; NSD, neurosensory disturbance.

of these, with little improvement in NSDs over time; $86 \%$ of patients still had symptoms after 2 years.

When comparing sensory profiles, mechanical and thermal hyperesthesia and mixed profiles had the worst outcome, with higher rates of long-term NSDs (ranging around 80\%). Approximately $40 \%$ of patients with a sensory loss profile had persistent NSDs after 2 years.

\section{Discussion}

\subsection{Main findings}

After the occurrence of trigeminal nerve injury, there was a high tendency toward persistent NSDs in this study. Sixty percent of patients who visited our tertiary center had symptoms that persisted for more than 3 months. This is in line with findings by Bagheri and Meyer, who reported permanent inferior alveolar injury in $78 \%$ of nerve injury patients after third molar surgery and persistent lingual nerve injury in $46 \%$ of such patients. ${ }^{1,2,21,27}$ Furthermore, Libersa et al. ${ }^{24}$ evaluated insurance records and reported a permanent injury in $22 \%$ of nerve injury cases after third molar surgery, $15 \%$ of cases after endodontic-related injury, and $75 \%$ of cases after implant-related injury. Although high variance exists, there seems to be a relatively high conversion rate to permanent NSDs after nerve injury has occurred.

\subsection{Patient profiles and predictors}

As clinicians and researchers, we know that not every nerve injury presents or evolves in the same way. Increasing numbers of studies have demonstrated the usefulness of phenotyping patients based on multiparametric data. ${ }^{40}$ In the future, it is hoped that this phenotyping will allow cost-effective treatment strategies to be tailored to each patient. ${ }^{14}$

The reported multivariable prediction model based on preoperative and perioperative factors was able to identify $77 \%$ of patients with long-term NSDs. The following clinical predictors were statistically significant: (1) sex, (2) initiating event (all except implant placement), and (3) presence of thermal hyperesthesia.

Females were almost 3 times more likely than males to have persistent NSDs. Similarly, a study by Selvi et al. reported a fivefold increase in NSDs in females compared with males. ${ }^{39}$ These authors also reported that older age and a close relationship between the third molar and the inferior alveolar nerve are associated with PTTNs after third molar surgery.

We also reported that patients with thermal hyperesthesia were 16 times more likely to have persistent NSDs. A recent report of PTNP demonstrated that increased patient age and an allodynia signature are significant factors that predict permanency of neuropathy. ${ }^{36}$ The importance of sensory phenotyping is further supported by the finding of different treatment outcomes according to the nociceptor phenotype. ${ }^{40}$ This study could not reveal unequivocal associations between treatment or nontreatment and outcome measures being persistence of NSD or final QoL.

One follow-up study by Pigg et al. evaluated 37 patients with persistent dentoalveolar pain, which is likely to be a neuropathic pain. ${ }^{32}$ These authors illustrated a similar symptom course as in this report. However, they were unable to detect predictive factors, including sensory profiles, for persistent pain after 7 years of follow-up. A low baseline pain score was the only predictor for symptom resolution, although no stratification was performed for etiology or injured nerve branch. 


\section{Table 6}

Bivariate correlation analysis between patient-related and surgery-related factors and QoL measured by the EQ-5D-5L VAS health state.

\begin{tabular}{|c|c|c|}
\hline Characteristic & Mean QoL health state (SD) & Test of correlation \\
\hline Age & - & $\begin{array}{l}\mathrm{r}_{\mathrm{s}}=-0.299 \\
P<0.0005 \\
\mathrm{n}=190\end{array}$ \\
\hline $\begin{array}{l}\text { Gender } n(\%) \\
\quad \text { Male } \\
\text { Female }\end{array}$ & $\begin{array}{l}74.36(17.60) \\
68.30(20.70)\end{array}$ & $\begin{array}{l}\mathrm{r}_{\mathrm{pb}}=-0.146 \\
P=0.044 \\
\mathrm{n}=190\end{array}$ \\
\hline $\begin{array}{l}\text { Smoker n (\%) } \\
\quad \text { No } \\
\text { Yes }\end{array}$ & $\begin{array}{l}75.24(16.65) \\
66.29(21.54)\end{array}$ & $\begin{array}{l}\tau \mathrm{b}=-0.156 \\
P=0.078 \\
\mathrm{n}=93\end{array}$ \\
\hline $\begin{array}{l}\text { Injured nerve } \\
\text { Inferior alveolar nerve n (\%) } \\
\quad \text { No } \\
\text { Yes }\end{array}$ & $\begin{array}{l}71.16(19.72) \\
69.77(20.01)\end{array}$ & $\begin{array}{l}\mathrm{r}_{\mathrm{pb}}=-0.035 \\
P=0.629 \\
\mathrm{n}=190\end{array}$ \\
\hline $\begin{array}{l}\text { Lingual nerve n (\%) } \\
\quad \text { No } \\
\text { Yes }\end{array}$ & $\begin{array}{l}68.61(19.93) \\
81.00(15.78)\end{array}$ & $\begin{array}{l}\mathrm{r}_{\mathrm{pb}}=0.222 \\
P=0.002 \\
\mathrm{n}=190\end{array}$ \\
\hline $\begin{array}{l}\text { Maxillary nerve } n(\%) \\
\text { No } \\
\text { Yes }\end{array}$ & $\begin{array}{l}72.64(19.23) \\
66.82(20.40)\end{array}$ & $\begin{array}{l}\mathrm{r}_{\mathrm{pb}}=-0.143 \\
P=0.049 \\
\mathrm{n}=190\end{array}$ \\
\hline
\end{tabular}

\begin{tabular}{|c|c|c|}
\hline \multicolumn{3}{|l|}{ Initiating event } \\
\hline \multicolumn{3}{|c|}{ Local anesthesia n (\%) } \\
\hline No & $70.35(20.06)$ & $r_{p b}=0.026$ \\
\hline Yes & $73.60(8.20)$ & $\begin{array}{l}P=0.719 \\
\mathrm{n}=190\end{array}$ \\
\hline \multicolumn{3}{|c|}{ Third molar surgery n (\%) } \\
\hline No & $67.36(19.57)$ & $r_{p b}=0.284$ \\
\hline Yes & $80.66(17.24)$ & $\begin{array}{l}P<0.0005 \\
n=190\end{array}$ \\
\hline \multicolumn{3}{|c|}{ Tooth extraction n (\%) } \\
\hline No & $70.59(20.08)$ & $r_{p b}=-0.016$ \\
\hline \multirow[t]{2}{*}{ Yes } & $69.73(18.89)$ & $P=0.822$ \\
\hline & & $\mathrm{n}=190$ \\
\hline \multicolumn{3}{|c|}{ Endodontic treatment n (\%) } \\
\hline No & $70.43(19.89)$ & $r_{p b}=0.001$ \\
\hline \multirow[t]{2}{*}{ Yes } & $70.50(19.80)$ & $P=0.989$ \\
\hline & & $n=190$ \\
\hline \multicolumn{3}{|c|}{ Dental implant placement n (\%) } \\
\hline No & $70.48(19.72)$ & $r_{p b}=-0.006$ \\
\hline \multirow[t]{2}{*}{ Yes } & $70.13(21.08)$ & $P=0.937$ \\
\hline & & $n=190$ \\
\hline \multicolumn{3}{|l|}{ Clinical findings } \\
\hline \multicolumn{3}{|l|}{ Duration n (\%) } \\
\hline Constant & $69.14(19.99)$ & $r_{p b}=0.154$ \\
\hline \multirow[t]{2}{*}{ Intermittent } & 77.48 (15.72) & $P=0.060$ \\
\hline & & $n=150$ \\
\hline \multicolumn{3}{|l|}{ Persistency n (\%) } \\
\hline Temporary & $80.86(10.84)$ & $\tau b=-0.306$ \\
\hline \multirow[t]{2}{*}{ Persistent } & $65.68(21.31)$ & $P<0.0005$ \\
\hline & & $n=187$ \\
\hline \multirow[t]{3}{*}{ Pain VAS score } & - & $r_{s}=-0.446$ \\
\hline & & $P<0.0005$ \\
\hline & & $\mathrm{n}=93$ \\
\hline \multicolumn{3}{|l|}{ Pain n (\%) } \\
\hline No & - & - \\
\hline Yes & $70.44(19.83)$ & \\
\hline Sensory loss n (\% & & \\
\hline
\end{tabular}


Table 6 (continued)

\begin{tabular}{|c|c|c|}
\hline Characteristic & Mean QoL health state (SD) & Test of correlation \\
\hline No & $64.53(21.79)$ & $\tau b=0.246$ \\
\hline Yes & $76.53(15.66)$ & $P<0.0005$ \\
\hline & & $\mathrm{n}=190$ \\
\hline \multicolumn{3}{|l|}{ Thermal hyperesthesia n (\%) } \\
\hline No & $71.04(19.95)$ & $r_{p b}=-0.067$ \\
\hline Yes & $67.55(19.31)$ & $P=0.358$ \\
\hline & & $n=190$ \\
\hline \multicolumn{3}{|l|}{ Mechanical hyperesthesia n (\%) } \\
\hline No & $71.70(19.30)$ & $r_{p b}=-0.099$ \\
\hline \multirow[t]{2}{*}{ Yes } & $67.41(20.90)$ & $P=0.175$ \\
\hline & & $n=190$ \\
\hline Number of other pain diagnoses & - & $r_{s}=-0.296$ \\
\hline & & $P<0.0005$ \\
\hline & & $\mathrm{n}=190$ \\
\hline \multicolumn{3}{|l|}{ Treatment } \\
\hline \multicolumn{3}{|l|}{ Any treatment n (\%) } \\
\hline No & $66.68(24.66)$ & $r_{p b}=0.063$ \\
\hline \multirow[t]{2}{*}{ Yes } & 70.85 (19.26) & $P=0.386$ \\
\hline & & $\mathrm{n}=190$ \\
\hline \multicolumn{3}{|l|}{ Systemic treatment n (\%) } \\
\hline No & $67.14(23.48)$ & $r_{p b}=0.060$ \\
\hline \multirow[t]{2}{*}{ Yes } & $70.87(19.34)$ & $P=0.408$ \\
\hline & & $n=190$ \\
\hline \multicolumn{3}{|l|}{ Topical treatment n (\%) } \\
\hline No & $71.62(20.13)$ & $r_{p b}=-0.124$ \\
\hline \multirow[t]{2}{*}{ Yes } & $65.36(17.86)$ & $P=0.088$ \\
\hline & & $\mathrm{n}=190$ \\
\hline \multicolumn{3}{|l|}{ Surgical treatment n (\%) } \\
\hline No & $70.94(19.26)$ & $r_{p b}=-0.087$ \\
\hline \multirow[t]{2}{*}{ Yes } & $64.53(25.69)$ & $P=0.231$ \\
\hline & & $n=190$ \\
\hline
\end{tabular}

(1) Where both dependent and independent variables were continuous, only the Spearman correlation coefficient is given. (2) No valid cases were available in the category of "no pain" to assess correlation with their health state.

SD, standard deviation; VAS, visual analogue scale; $r_{\mathrm{pb}}$, point-biserial correlation; $r_{\mathrm{S}}$, Spearman correlation; $\tau_{\mathrm{b}}$, Kendall tau-b correlation.

\subsection{Pain intensity}

This study further confirms age-related and gender-related associations with more severe pain. ${ }^{4}$ Third molar surgery was less likely to be associated with moderate to severe pain. Other initiating events were not statistically significant associated with moderate to severe pain. Small numbers per variable may explain why most variables did not contribute significantly to the analysis.

It was striking that PTTN at the level of the maxilla was 7 times more likely to be associated with moderate to severe pain. Lingual and inferior alveolar nerve-related injuries were less likely to result in moderate to severe pain. This strengthens the clinical suspicion that the degree of nerve damage does not necessarily correlate with the final pain intensity. ${ }^{25}$ It even seems that PTTN at the level of the maxilla, where one finds mainly submillimetric peripheral nerve branches and usually undergoes less extensive surgery, poses a higher risk than mandibular wisdom tooth surgery, which is considered more invasive, and takes place at the level of a 2- to 3-mm thick lingual or inferior alveolar nerve. It is true that even minimal interventions such as root canal treatment may result in persistent pain. ${ }^{30}$

More research will be needed to assess the role of nerve injury classifications in prediction models. ${ }^{13}$ One interesting follow-up study would be to investigate the role of nerve fiber distributions and density in relation to PTNP and its triggering mechanisms.

\subsection{Course of symptoms}

Most global improvement occurred within the first 3 months after trauma was inflicted. Notably, the evolution was markedly different between certain patient groups, based on the previously discussed variables. For example, a patient who had lingual nerve damage after wisdom tooth surgery with a sensory loss phenotype had a better chance of spontaneous recovery compared with a patient who had inferior alveolar nerve damage after endodontic treatment and complained of thermal hyperesthesia. The Kaplan-Meier distributions highlight the different clinical course, and perhaps different underlying pathophysiology, between cohorts.

Other studies have reported a similar cut-off for spontaneous recovery. ${ }^{7,29}$ Time to recovery is an important factor to consider. For example, there is support for the theory that faster systemic treatment of postsurgical neuropathies or CPSP can lead to better outcomes or even avoid the development of CPSP or neuropathic pain. ${ }^{45}$ Furthermore, in the case of severe nerve injury, microsurgical neural repair should be performed within 3 months of the injury occurrence to improve outcomes. ${ }^{22}$ Another study, by Tabrizi et al., ${ }^{44}$ revealed a significant association between time to treatment and neurosensory recovery after mandibular body fractures. This finding illustrates the importance of early diagnosis in patients with nerve injury. Nevertheless, further research is needed to identify the most cost-effective treatments for the different phenotypes of patients with nerve injury.

\subsection{Quality of life}

In the end, the QoL is what matters most to our patients. We identified a significant difference between patients who sustained 
Table 7

Multiple regression model assessing the relationship between patients' quality of life health state and patient-related and surgery-related factors.

\begin{tabular}{|c|c|c|c|c|c|c|c|c|}
\hline \multirow[t]{2}{*}{ Characteristic } & \multirow[t]{2}{*}{ B } & \multirow[t]{2}{*}{ SE B } & \multirow[t]{2}{*}{$P$} & \multicolumn{2}{|c|}{ 95\% Cl for B } & \multirow[t]{2}{*}{$\boldsymbol{\beta}$} & \multirow[t]{2}{*}{$R^{2}$} & \multirow[t]{2}{*}{$\Delta R^{2}$} \\
\hline & & & & Lower & Upper & & & \\
\hline Model & & & & & & & 0.520 & 0.415 \\
\hline Gender & 2.30 & 11.48 & 0.508 & -4.59 & 9.20 & 0.06 & & \\
\hline Age & -0.15 & -0.13 & 0.209 & -0.39 & 0.09 & -0.13 & & \\
\hline \multicolumn{9}{|l|}{ Injured nerve } \\
\hline Inferior alveolar nerve & -5.29 & 6.35 & 0.407 & -17.95 & 7.37 & -0.14 & & \\
\hline Lingual nerve & 1.61 & 6.71 & 0.811 & -11.76 & 14.99 & 0.04 & & \\
\hline Maxillary nerve & -7.30 & 7.23 & 0.316 & -21.72 & 7.11 & -0.17 & & \\
\hline \multicolumn{9}{|l|}{ Initiating event } \\
\hline Local anesthesia & -1.43 & 10.00 & 0.887 & -21.36 & 18.51 & -0.01 & & \\
\hline Third molar surgery & 8.37 & 4.67 & 0.077 & -0.94 & 17.67 & 0.22 & & \\
\hline Extraction & 7.63 & 5.74 & 0.188 & -3.80 & 19.07 & 0.14 & & \\
\hline Endodontic treatment & 11.53 & 8.46 & 0.177 & -5.32 & 28.38 & 0.13 & & \\
\hline Implant placement & 16.74 & 6.15 & 0.008 & 4.49 & 28.99 & 0.25 & & \\
\hline \multicolumn{9}{|l|}{ Clinical findings } \\
\hline Persistent NSD & -8.54 & 4.07 & 0.039 & -16.65 & -0.43 & -0.22 & & \\
\hline Pain VAS score & -2.98 & 1.01 & 0.004 & -4.99 & -0.97 & -0.54 & & \\
\hline Sensory loss & -12.90 & 7.16 & 0.076 & -27.17 & 1.38 & -0.32 & & \\
\hline Thermal hyperesthesia & -5.84 & 5.37 & 0.281 & -16.54 & 4.86 & -0.11 & & \\
\hline Mechanical hyperesthesia & -2.64 & 4.84 & 0.587 & -12.28 & 7.00 & -0.05 & & \\
\hline Any treatment & 10.60 & 5.00 & 0.037 & 0.64 & 20.57 & 0.20 & & \\
\hline Constant & 91.22 & 11.48 & $<0.0005$ & 68.35 & 114.09 & & & \\
\hline
\end{tabular}

Gender is for females compared with males.

$\mathrm{B}$, unstandardized regression coefficient; NSD, neurosensory disturbance SE B, standard error of the coefficient; $\mathrm{Cl}$, confidence interval; VAS, visual analog scale (0-10); $R^{2}$, coefficient of determination; $\Delta R^{2}$, adjusted $R^{2}$.

transient nerve injuries (EQ-5D VAS $80 \pm 1.4)$ and patients with persistent injuries $(65 \pm 1.9)$. When this was put into perspective with national population data, we noticed a worse QoL in the patients with persistent symptoms. Szende et al. reported that the mean Belgian EQ-5D VAS score for the 45 to 54 year age group is $77.2 .^{42}$ We also observed that approximately half of all patients with temporary or persistent nerve damage reported health problems. This proportion is markedly higher than the average national figures, which are approximately $30 \% .{ }^{42}$

Previous studies have identified a significant psychosocial burden in patients with trigeminal nerve injuries. ${ }^{9,41}$ Smith et al. also reported that the severity of pain is related to poorer QoL in such patients. ${ }^{41}$ These results support our finding of higher quality-of-life scores in patients with transient damage. Indeed, in
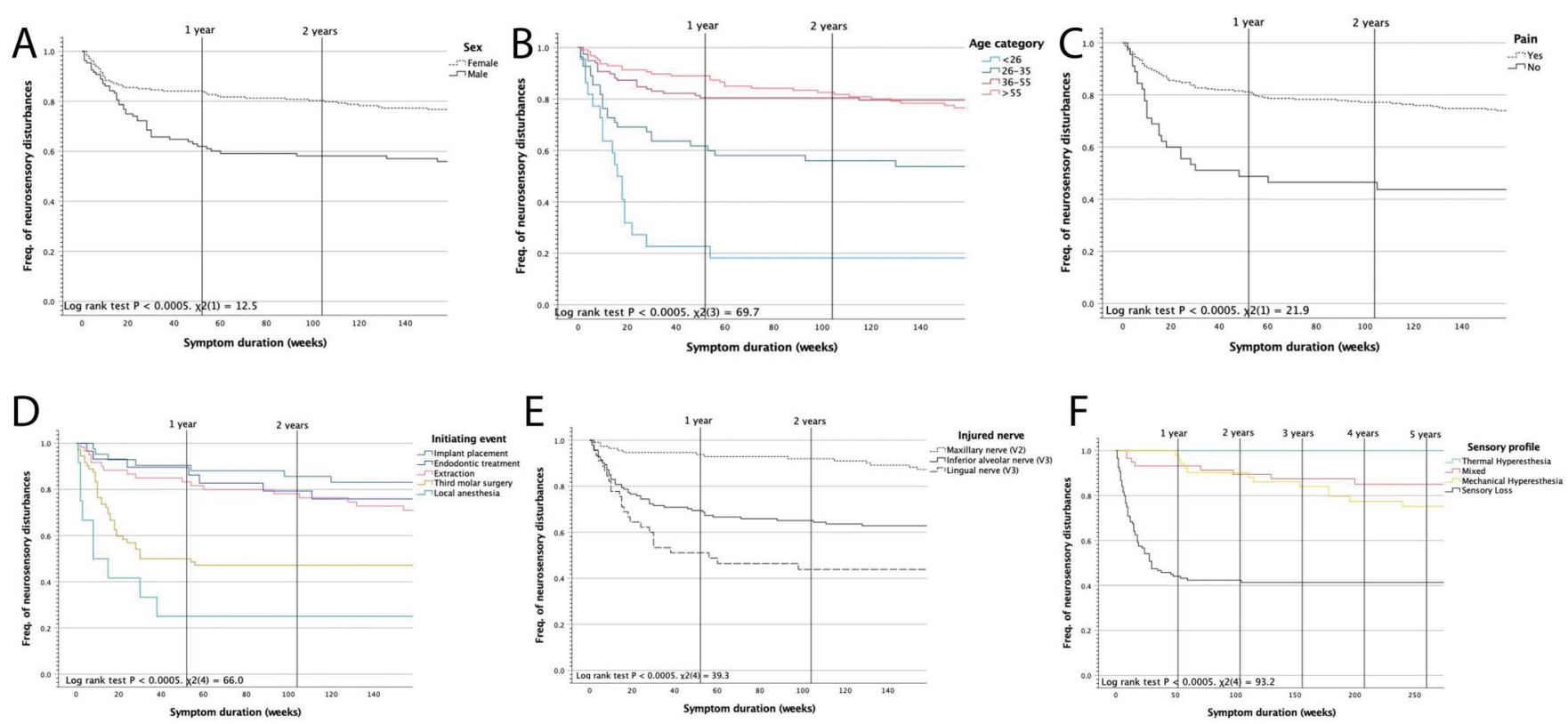

Figure 1. Kaplan-Meier analysis of neurosensory disturbances (NSDs) over time comparing sex (A), age (B), painful and nonpainful posttraumatic trigeminal neuropathies (PTTNs) (C), initiating event (D), injured nerve branch (E), and sensory profile (F). Between-group pairwise comparisons were all statistically significant $(P<0.0005$, pairwise log-rank test). 
these patients, pain was present less frequently and was also less severe. Together, these findings demonstrate the importance of paying attention to psychosocial impacts and improving patients' QoL.

\subsection{Strengths and limitations}

To the best of our knowledge, this study is the first to investigate a large population of patients with PTTN and PTNP with a long follow-up. For the first time, risk factors for developing persistent PTTNs were identified and quantified. In addition, the course of symptoms was plotted to compare cohorts based on sex, etiology, injured nerve, presence of pain, and sensory profile. Such longitudinal data are unique in the current literature. However, the different symptom courses of patients with PTNP hide an underlying pathophysiology that remains insufficiently understood. In addition, the lack of universally accepted treatment protocols makes it difficult to understand treatment effects on outcome.

Limitations of this study included its retrospective nature and its tertiary setting, which may have led to selection bias. Sensory testing was mainly qualitative in nature, which comes with its own limitations. In addition, psychosocial measures were limited. Because of the large number of variables, some variables had few events per predictor, which may explain the contradictory results of some of the bivariate and multivariate predictions. Moreover, the data-driven approach that we used on the retrospective data should be externally validated.

\subsection{Implications}

After a trigeminal nerve injury was inflicted, there was a high tendency toward persistent NSDs in patients in our tertiary center. This is an alarming finding considering that dental, oral, and maxillofacial surgery is one of the most frequently performed procedures. Thus, investigating preventive strategies and educating clinicians about PTTNs should be on the top of the academic agenda.

Most global improvement was observed within the first 3 months after trauma was inflicted. Multiple patient-related and surgery-related factors played a role in neurosensory recovery. The proposed multivariable prediction model may aid in predicting an individualized estimate of neurosensory recovery, but further prospective validation is needed. Important factors were identified that might aid the design of a future prospective registry study for patients with NSDs.

\section{Conflict of interest statement}

The authors have no conflicts of interest to declare.

\section{Acknowledgments}

The authors thank Steffen Fieuws from the Interuniversity Institute for Biostatistics and Statistical Bioinformatics, KU Leuven, for his statistical support. The authors also thank Bronwen Gardner, $\mathrm{PhD}$, from Edanz Group (https://en-author-services.edanz.com/ ac) for editing a draft of this manuscript and helping to draft the abstract.

\section{Appendix A. Supplemental digital content}

Supplemental digital content associated with this article can be found online at http://links.Iww.com/PAIN/B435.

\author{
Article history: \\ Received 2 February 2021 \\ Received in revised form 28 June 2021 \\ Accepted 6 July 2021 \\ Available online 13 July 2021
}

\section{References}

[1] Bagheri SC, Meyer RA, Cho SH, Thoppay J, Khan HA, Steed MB. Microsurgical repair of the inferior alveolar nerve: success rate and factors that adversely affect outcome. J Oral Maxill Surg 2012;70:1978-90.

[2] Bagheri SC, Meyer RA, Khan HA, Kuhmichel A, Steed MB. Retrospective review of microsurgical repair of 222 lingual nerve injuries. J Oral Maxill Surg 2010;68:715-23.

[3] Boogaard S, Heymans MW, Patijn J, de Vet HCW, Faber CG, Peters ML, Loer SA, Zuurmond WWA, Perez RSGM. Predictors for persistent neuropathic pain - a delphi survey. Pain Physician 2011;14:559-68.

[4] Boogaard S, Heymans MW, de Vet HCW, Peters ML, Loer SA, Zuurmond WWA, Perez RSGM. Predictors of persistent neuropathic pain-A systematic review. Pain physician 2015;18:433-57.

[5] Box GEP, Tidwell PW. Transformation of the independent variables. Technometrics 1962;4:531-50.

[6] Chapman CR, Vierck CJ. The transition of acute postoperative pain to chronic pain: an integrative overview of research on mechanisms. The $J$ Pain 2017;18:359.e1-359.e38.

[7] Cheung LK, Leung YY, Chow LK, Wong MCMM, Chan EKKK, Fok YH. Incidence of neurosensory deficits and recovery after lower third molar surgery: a prospective clinical study of 4338 cases. Int J Oral Maxill Surg 2010;39:320-6.

[8] Collins GS, Reitsma JB, Altman DG, Moons KGM. Transparent reporting of a multivariable prediction model for individual prognosis or diagnosis (TRIPOD): the TRIPOD statement. Ann Intern Med 2015; 162:55-63.

[9] Van der Cruyssen F, Peeters F, Gill T, De Laat A, Jacobs R, Politis C, Renton T. Signs and symptoms, quality of life and psychosocial data in 1331 post-traumatic trigeminal neuropathy patients seen in two tertiary referral centres in two countries. J Oral Rehabil 2020;47:1212-21.

[10] Devine M, Modgill O, Renton T. Mandibular division trigeminal nerve injuries following primary endodontic treatment. A case series. Aust Endod J 2017;43:56-65.

[11] Feizerfan A, Sheh G, Bhb GS, Fafrm M, Ffpmanzca R, Feizerfan A, Sheh G. Transition from acute to chronic pain. PAIN 2015;15:98-102.

[12] Finnerup NB, Haroutounian S, Kamerman P, Baron R, Bennett DLH, Bouhassira D, Cruccu G, Freeman R, Hansson P, Nurmikko T, Raja SN, Rice ASC, Serra J, Smith BH, Treede RD, Jensen TS. Neuropathic pain: an updated grading system for research and clinical practice. PAIN 2016; 157:1599-606.

[13] Finnerup NB, Kuner R, Jensen TS. Neuropathic pain: from mechanisms to treatment. Physiol Rev 2021;101:259-301.

[14] Forstenpointner J, Otto J, Baron R. Individualized neuropathic pain therapy based on phenotyping. PAIN 2017;159:569-75.

[15] Haroutiunian S, Nikolajsen L, Finnerup NB, Jensen TS. The neuropathic component in persistent postsurgical pain: a systematic literature review. PAIN 2013;154:95-102.

[16] Hosmer DW, Lemeshow S, Sturdivant RX. Applied Logistic Regression. New York: John Wiley and Sons, 3rd ed, 2013.

[17] IHS (Headache Classification Committee of the International Headache Society), Olesen J. The international classification of Headache disorders, 3rd edition. Cephalalgia 2018;33:629-808.

[18] International classification of orofacial pain, 1st edition (ICOP). Cephalalgia 2020;40:129-221.

[19] Katz J, Seltzer Z. Transition from acute to chronic postsurgical pain: risk factors and protective factors. Expert Rev Neurotherapeutics 2009;9: 723-44.

[20] Kehlet H, Jensen TS, Woolf CJ. Persistent postsurgical pain: risk factors and prevention. The Lancet 2006;367:1618-25.

[21] Klazen Y, Van der Cruyssen F, Vranckx M, Van Vlierberghe M, Politis C, Renton $\mathrm{T}$, Jacobs $\mathrm{R}$. latrogenic trigeminal post-traumatic neuropathy: a retrospective two-year cohort study. Int J Oral Maxill Surg 2018;47: 789-93.

[22] Kushnerev E, Yates JM. Evidence-based outcomes following inferior alveolar and lingual nerve injury and repair: a systematic review. J Oral Rehabil 2015;42:786-802.

[23] Langley PC, Van Litsenburg C, Cappelleri JC, Carroll D. The burden associated with neuropathic pain in Western Europe. J Med Econ 2013; 16:85-95. 
[24] Libersa P, Savignat M, Tonnel A. Neurosensory disturbances of the inferior alveolar nerve: a retrospective study of complaints in a 10-year period. J Oral Maxill Surg 2007;65:1486-9.

[25] Meewis J, Renton T, Jacobs R, Politis C, Van der Cruyssen F. Posttraumatic trigeminal neuropathy: correlation between objective and subjective assessments and a prediction model for neurosensory recovery. J Headache Pain 2021;22:44.

[26] Melek LN, Smith JG, Karamat A, Renton T. Comparison of the neuropathic pain symptoms and psychosocial impacts of trigeminal neuralgia and painful posttraumatic trigeminal neuropathy. J Oral Facial pain headache 2019;33:77-88.

[27] Meyer RA, Bagheri SC. Nerve injuries from mandibular third molar removal. Atlas Oral Maxill Surg Clin North America 2011;19:63-78.

[28] Miloro MM. Trigeminal Nerve Injuries. 1st ed. Berlin, Heidelberg: Springer. doi: 10.1007/978-3-642-35539-4.

[29] Nguyen E, Grubor D, Chandu A. Risk factors for permanent injury of inferior alveolar and lingual nerves during third molar surgery. J Oral Maxill Surg 2014;72:2394-401.

[30] Nixdorf DR, Law AS, Lindquist K, Reams GJ, Cole E, Kanter K, Nguyen RHN, Harris DR. Frequency, impact, and predictors of persistent pain after root canal treatment: a national dental PBRN study. PAIN 2016;157:159-65.

[31] Peduzzi P, Concato J, Kemper E, Holford TR, Feinstein AR. A simulation study of the number of events per variable in logistic regression analysis. J Clin Epidemiol 1996;49:1373-9.

[32] Pigg M, Svensson P, Drangsholt M, List T. Seven-year follow-up of patients diagnosed with atypical odontalgia: a prospective study. J Orofacial Pain 2013;27:151-64.

[33] Renton T, Adey-Viscuso D, Meechan JG, Yilmaz Z. Trigeminal nerve injuries in relation to the local anaesthesia in mandibular injections. $\mathrm{Br}$ Dental J 2010;209:452-3.

[34] Renton T, Van der Cruyssen F. Diagnosis, pathophysiology, management and future issues of trigeminal surgical nerve injuries. Oral Surg 2019. doi: 10.1111/ors. 12465 .

[35] Rosén B, Lundborg G. A model instrument for the documentation of outcome after nerve repair. J Hand Surg 2000;25:535-43.
[36] Ryu JW, Ahn JM, Yoon CL. Clinical predictors of permanent neuropathy in patients with peripheral painful traumatic trigeminal neuropathy. J Oral Med Pain 2016;41:118-25.

[37] Schug SA, Bruce J. Risk stratification for the development of chronic postsurgical pain. Schmerz 2018;32:471-6.

[38] Schug SA, Lavand'homme P, Barke A, Korwisi B, Rief W, Treede R-D. The IASP classification of chronic pain for ICD-11: chronic postsurgical or posttraumatic pain. PAIN 2019;160:45-52.

[39] Selvi F, Dodson TB, Nattestad A, Robertson K, Tolstunov L. Factors that are associated with injury to the inferior alveolar nerve in high-risk patients after removal of third molars. Br J Oral Maxill Surg 2013;51:868-73.

[40] Sindrup SH, Vollert J, Demant DT, Maier C, Lund K, Segerdahl M, Finnerup NB, Jensen TS. The effect of oxcarbazepine in peripheral neuropathic pain depends on pain phenotype: a randomised, double-blind, placebocontrolled phenotype-stratified study. PAIN 2014;155:2263-73.

[41] Smith JG, Elias L-A, Yilmaz Z, Barker S, Shah K, Shah S, Renton T. The psychosocial and affective burden of posttraumatic neuropathy following injuries to the trigeminal nerve. J orofacial pain 2013;27:293-303.

[42] Szende A, Janssen B, Cabases J. Self-Reported Population Health: An International Perspective based on EQ-5D. Dordrecht: Springer, 1997.

[43] Tabachnick BG, Fidell LS. Using multivariate statistics. 6th ed, 2012 Boston: Pearson Education.

[44] Tabrizi R, Pourdanesh F, Khoshnik PL, Centenero SA-H. Does the lag time between injury and treatment play a role in recovery of inferior alveolar nerve neurosensory disturbances following mandibular body fracture?. J Craniofac Surg 2019;30:2128-30.

[45] Tawfic Q, Kumar K, Pirani Z, Armstrong K. Prevention of chronic postsurgical pain: the importance of early identification of risk factors. J Anesth 2017;31:424-31.

[46] Vittinghoff E, McCulloch CE. Relaxing the rule of ten events per variable in logistic and cox regression. Am J Epidemiol 2007;165:710-18.

[47] Yilmaz Z, Ucer C, Scher E, Suzuki J, Renton T. A survey of the opinion and experience of UK dentists: Part 1: the incidence and cause of iatrogenic trigeminal nerve injuries related to dental implant surgery. Implant Dentistry 2016;25:638-45. 